\title{
Powerpoint as a Useful Tool in Corrective Osteotomies Calculation-Case Report and Presentation of the Method
}

\section{Powerpoint como una herramienta útil en el cálculo de las osteotomías correctivas-relato de caso y presentación del método}

\author{
Daniela Pérez ${ }^{1,2,3}$ Mariana da Rocha Sousa Camello Martins ${ }^{3,4}$ Montserrat del Valle ${ }^{5}$ Ángel Ferreres ${ }^{6}$ \\ 1 Orthopaedic Department, Hospital de Urgencias Asistencia Pública, \\ Santiago de Chile, Chile \\ 2 Department of Orthopedics and Traumatology, Universidad de \\ Chile, Santiago, Chile \\ ${ }^{3}$ Hand Surgery Fellow, Institut Kaplan, Barcelona, España \\ ${ }^{4}$ Department of Plastic and Reconstructive Surgery, Centro \\ Hospitalar Lisboa Central, Lisboa, Portugal \\ ${ }^{5}$ Hand Unit, Hospital Esperit Sant, Santa Coloma de Gramenet, \\ Barcelona, España \\ 6 Institut Kaplan, Barcelona, España \\ Rev Iberam Cir Mano 2019;47:48-55.
}

\begin{abstract}
Keywords

- osteotomy

- PowerPoint

- pronosupination

- malalignment
\end{abstract}

\section{Resumen}
Palabras clave
- osteotomía
- powerpoint
- pronosupinación
- desalineación

Malunion or congenital disorders of the forearm might lead to biomechanical alterations and change the pronosupination motion. Occasionally, an osteotomy should be performed to correct this malalignment. Several techniques have been reported, especially 3D modeling, which is not yet widely used due to its cost. The traditional method is still mostly performed, but sometimes it may be difficult to do the preplanning. In this paper, we explain an easy method, called "giro point" technique, to perform the calculation of osteotomies using commercially available software. We present six clinical cases with good functional results, in which the calculation was performed using this method. The method is easy to follow, with adequate surgicalradiological correlation.

Las deformidades congénitas o maluniones del antebrazo pueden generar alteraciones biomecánicas, cambiando la pronosupinación. Ocasionalmente, se recurre a una osteotomía para corregir la desalineación. La literatura reporta múltiples técnicas, con la modelación 3D en boga, pero dado su costo actual, no es usada masivamente. El método tradicional se sigue usando, sin embargo puede resultar dificultosa la planeación prequirúrgica. En este artículo se presenta una forma sencilla de realizar el cálculo de la osteotomía denominado método de "punto-giro," con un software comercial. Se presentan 6 casos, con buenos resultados funcionales, cuyos cálculos fueron hechos con este método. El método es fácil de seguir, con adecuada correlación quirúrgicoradiológica. received

July 2, 2018

accepted

March 27, 2019
DOI https://doi.org/

$10.1055 / \mathrm{s}-0039-1688567$. ISSN 1698-8396.
Copyright @ 2019 Thieme Revinter

Publicações Ltda, Rio de Janeiro, Brazil
License terms

c) $(1) \$$ 


\section{Introduction}

Although the osteotomies calculations have been primarily developed in the lower extremity, ${ }^{1,2}$ occasionally, one of these procedures must be performed in the upper extremity. The deformities may be secondary to a malunion or congenital disorders ${ }^{3}$ and may get worse during the growing period by altering the biomechanical relationship of the long bones in the forearm. In the presence of abnormal hand pronation and supination, it is vital to correct it with a surgical procedure, keeping in mind that the preoperative planning is the most important part.

The classic method of calculation is based in trigonometric measures taken in teleradiographs of the extremities. ${ }^{4}$ Paley inserted the concept of center of rotation of the angulation (CORA), and, from this point, it is decided where and how the osteotomies must be performed; either open or closed wedge. ${ }^{5}$ However, this method is focused on the lower extremities, mainly correcting the frontal plane, leaving the sagittal plane as secondary. Moreover, great importance is given to the mechanical axis, which is secondary in the upper extremity's corrections. $^{3,5}$

Presently, with the advance of new technology, alternative ways to perform this calculation are underway: tridimensional models based on CT scans ${ }^{1,2,6,7}$ or using calculus software tools. ${ }^{4}$ Although useful and very precise about establishing the cut points, the spread of these technologies is still difficult, since they remain high in cost (3D printers), or because special knowledge of the software (Autocad) is required for their use.

In 2008, Jones et al did validated a commercial software for angle measurement with a good intra and interobserver reliability. They called it "virtual goniometer", and it was based on PowerPoint (Microsoft Corp., Redmond, WA, USA)) tools, widely available and of intuitive use. ${ }^{8}$

Based on the classical Paley method for osteotomies, and taking care of the three planar axis corrections, we have established an easy method using digital conventional X-rays and PowerPoint software to do a systematized planning for the correction. We have found this method to be easy to follow, and with a good surgical correlation during the actual procedure.

\section{Indications and Contraindications}

Any deformities of the upper extremity can be calculated with the "giro point" technique. There is no contraindication for performing the "giro point" calculation.

\section{Technique}

The "giro point" technique

Nomenclature that will be used for the whole explanation: $\mathrm{nb}$ - normal bone; $\mathrm{db}$ - deviated bone; rnb- reverse normal bone

1. Take anteroposterior and lateral radiographs of both forearms, making sure that both joints (elbow and wrist) are visible, so that the full length of the radius and ulna can be seen. At this point, you can visualize which bone is affected (compatible with the physical exam).
2. Open a new file in the Microsoft PowerPoint software and copy all the images (total of 4) and gather them as the two anteroposterior views in one slide and the two lateral ones on another slide.

3. In each radiography and for each forearm bone, draw a line corresponding to the curvature of the present bones (-Figs. 1 and 2), and, then, copy those lines to another slide, always keeping the curvatures of each matching views together (-Fig. $\mathbf{3}$ ).

4. At this point, you will have one slide with four curvatures (two radius and two ulnae) for the anteroposterior view and another slide with other four curvatures (two radius and two ulnae) for the lateral views. In each of these slides do the reverse image of the [nb] curvature and compare with the $[\mathrm{db}]$ curvature (do it for the radius and for the ulna) (-Fig. 4).

5. From this moment, you will get two curvatures (one of the $\mathrm{db}$ and the other of the rnb) that will cross in one or more points, and those will signalize the surgical osteotomies. If they match or are very similar in the anteroposterior view and divergent in the lateral view you will have to make a volar/dorsal correction, but if you have a match in the lateral view and a mismatch in the anteroposterior view the surgical correction will have to be done at the coronal axis or in the radioulnar plane. Also, you will get the information of which of each bone segment is affected (distal, middle and/or proximal).

6. Make a double copy of the $[\mathrm{db}]$ curvature, and put them in parallel and nearby the [nb] curvature (-Fig. 5).

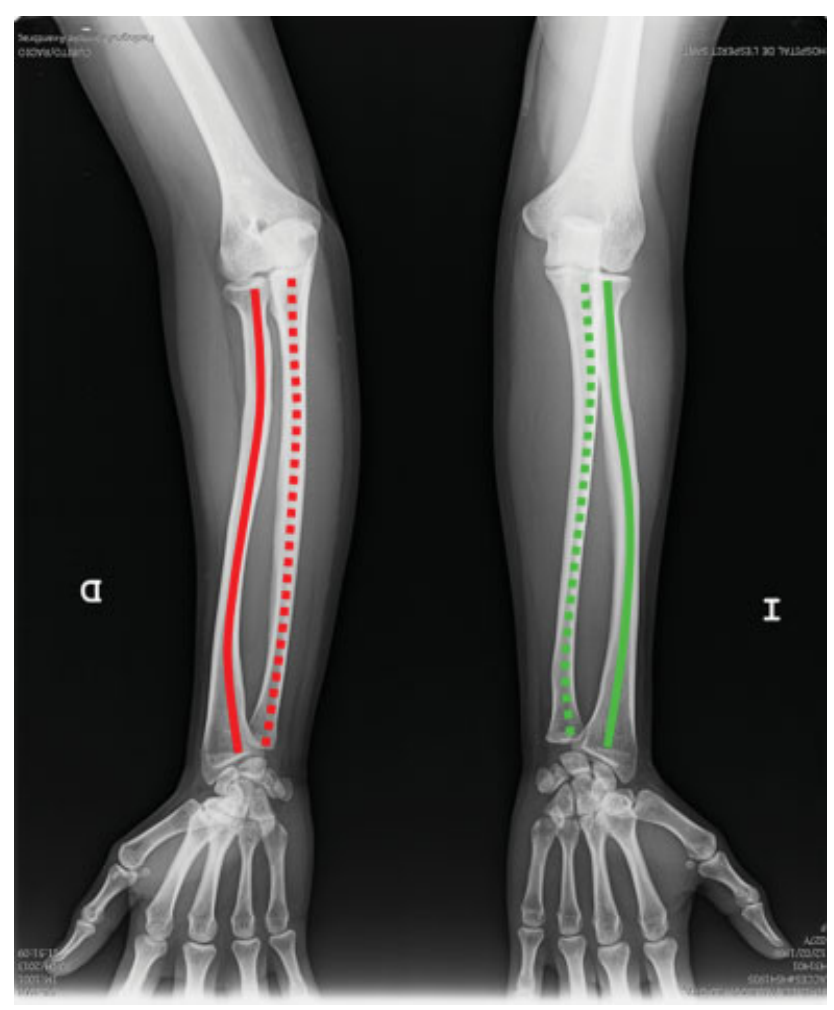

Fig. 1 Frontal X-ray, with the longitudinal axis marked. Red for the right arm, green for the left. Solid lines stand for the radius and dotted for ulnae. 

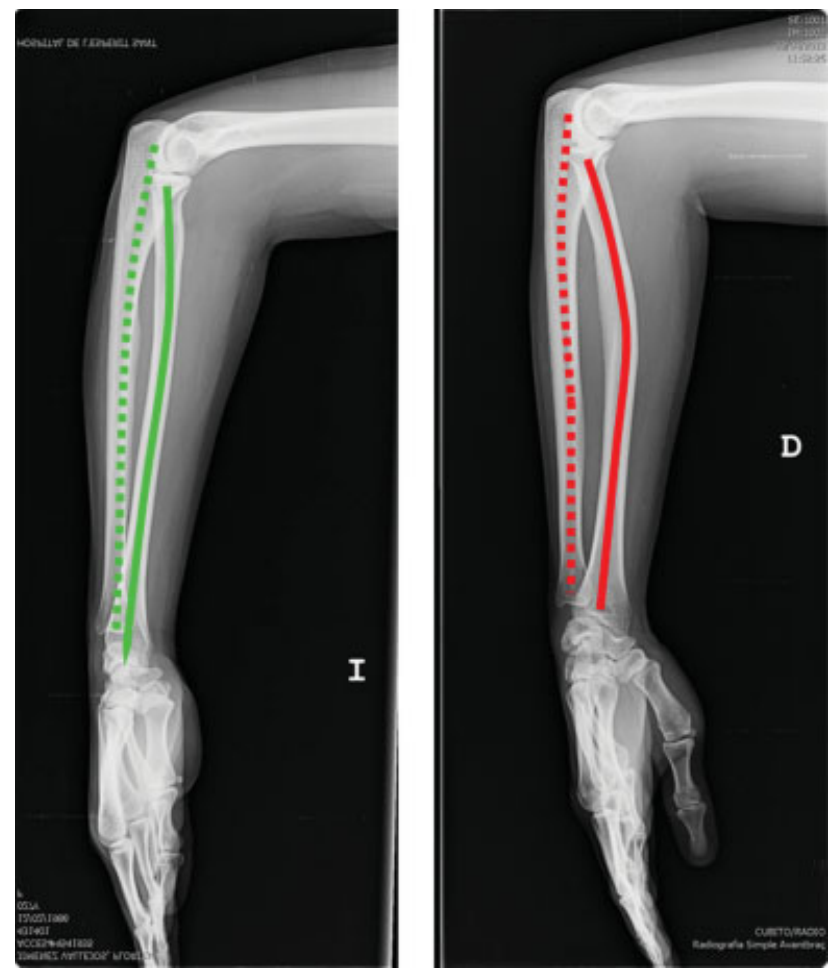

Fig. 2 Lateral X-ray, with the longitudinal axis marked. Red for the right arm, green for the left. Solid lines stand for the radius and dotted for ulnae.

7. Select each [db] curvature and erase the proximal part in one and the distal part in another, having as reference point, or cutting point, the convergence of the curvatures set before - in the program select each line, click in the right button of the computer mouse, select "edit points," and then option "eliminate points" ( - Fig. 6).

8. Now we have two separate short lines, one is parallel to the reverse image of the [nb] curvature and the other isn't (line divergent from the convergence point). To make this one parallel to [rnb] you will have to make a rotation of it, and that degree of rotation will tell you what is going to be the angulation of your corrective osteotomy. So, select the line divergent, go to option "Tools" -> "Rotation" -> "More options of rotations" -> "Size and Position." From this moment on, you will only work on the "Rotation" box, using the arrows to modify the angle of the selected line and make it more similar with the reverse image of the [nb] curvature ( - Fig. 7). At the end, that angle is going to be the one for the surgical osteotomy correction (-Fig.8).

9. Having the two short lines connected you will get a new one that is very similar with the reverse image of the [nb] curvature.

10. As for the second plane, you take the lateral X-ray views and repeat the same procedure ( - Figs. 9,10,11).

In the case a correction of the third plane is needed, a CT scan will be necessary. Then the calculation system is applied to the reference lines in the transverse plane. (-Fig. 12)

\section{Clinical Cases}

\section{Case 1}

The patient is a 27-year-old female; right-handed, manual worker. She related a childhood fracture of the right forearm with progressive pain and movement restriction. At the time of the first visit, she needed daily pain relief, with arch of motion of $40-5^{\circ}$ pronosupination and normal flexoextension. X-rays were performed, which confirmed a plastic deformation of the forearm, without any other lesions. The PowerPoint planning was done, and a 3D print model was printed to perform the osteotomy previously. The surgery was performed in September of 2015: open wedge osteotomies of radius and ulna via conventional approaches (Henry to the radius and posterior to ulna). The patient was put on a cast for the immediate
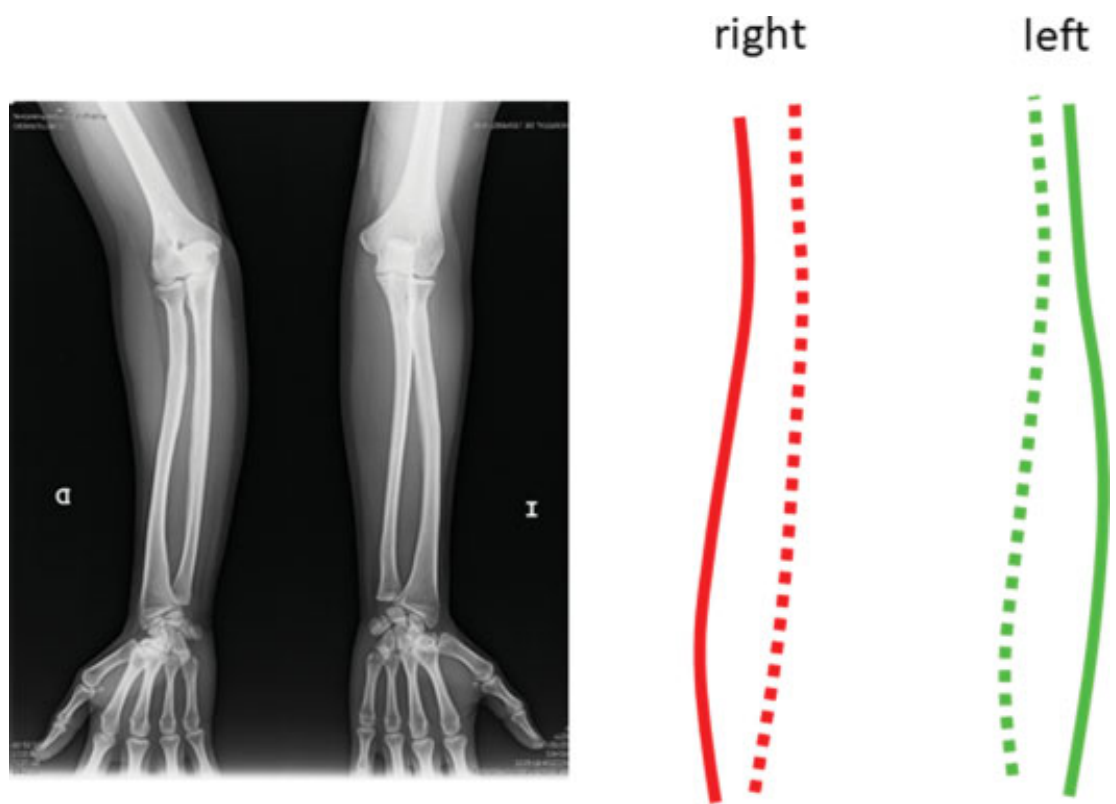

Fig. 3 Lines ready to start working with them. 


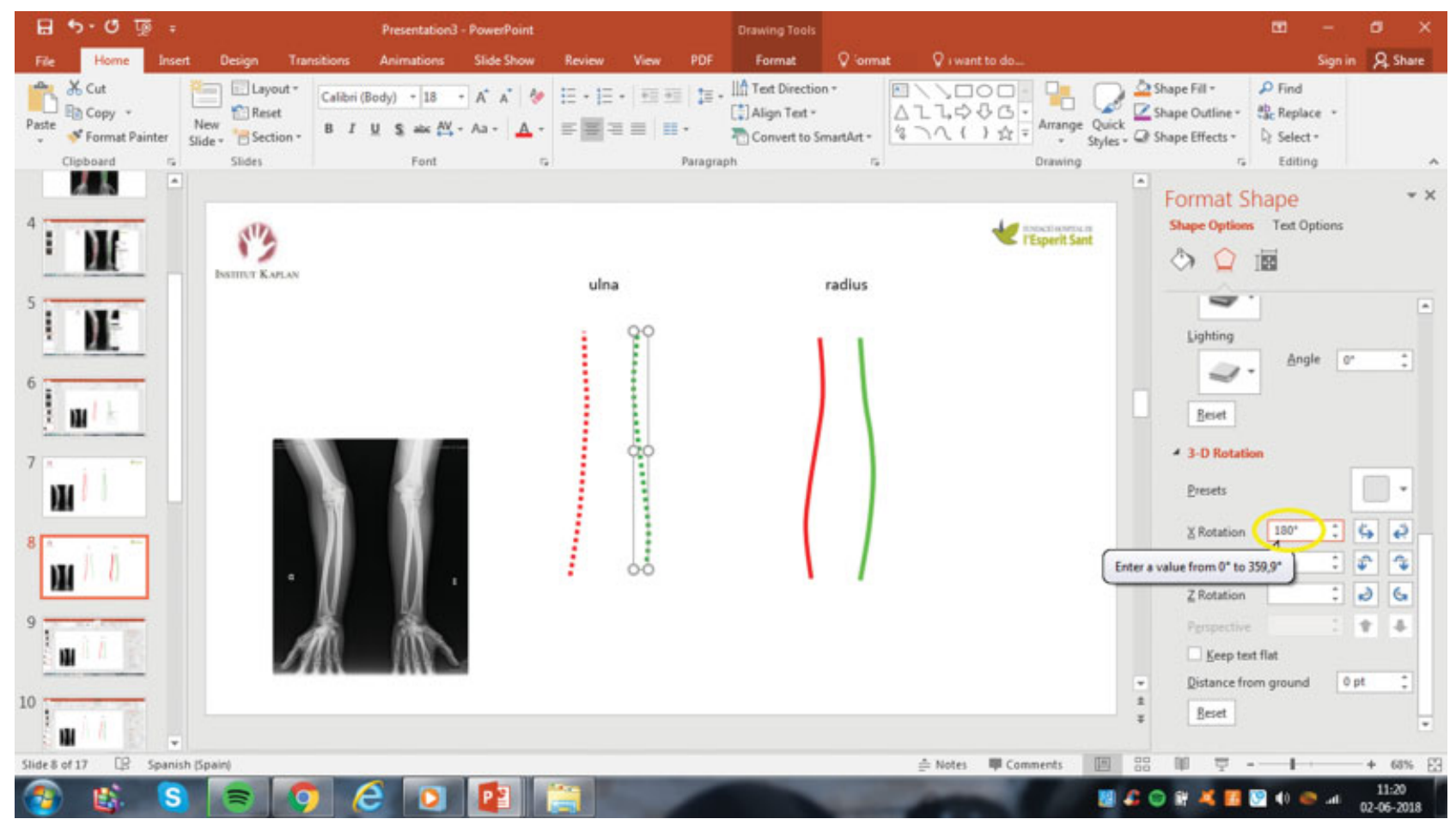

Fig. 4 Rotation of the normal bone.


Fig. 5 Edit points. Cut of the deviated bone at the point in which it crosses with the reverse normal bone.

postoperative and at 3 weeks, she was released to start therapy. The consolidation was complete at 4 months postsurgery. Afterwards, the ulnar side plate was removed due to hardware prominence, and scar treatment followed. At her last visit, in January 2018, the patient presented a pronosupination arch of $90-80^{\circ}$, was free of pain and doing her usual work.

\section{Case 2}

The patient was a 32 year/old male. Ulna fracture in 2015 with non-union. Previous distal osteotomy without correction. First evaluation, in February 2017, with supination deficiency and caput ulnae. Preoperative planning with the giro-point showed that an open-wedge osteotomy was needed. The surgery was performed in March, with iliac bone autograft. In June 2017, the fracture was consolidated with $20^{\circ}$ deficit of supination.

\section{Case 3}

The patient was a 23 years/o male. Left radius fracture in 2013. Failed primary osteosynthesis, with supination deficit. A corrective osteotomy was performed in March 2014, with complete consolidation 6 months after the surgery. 


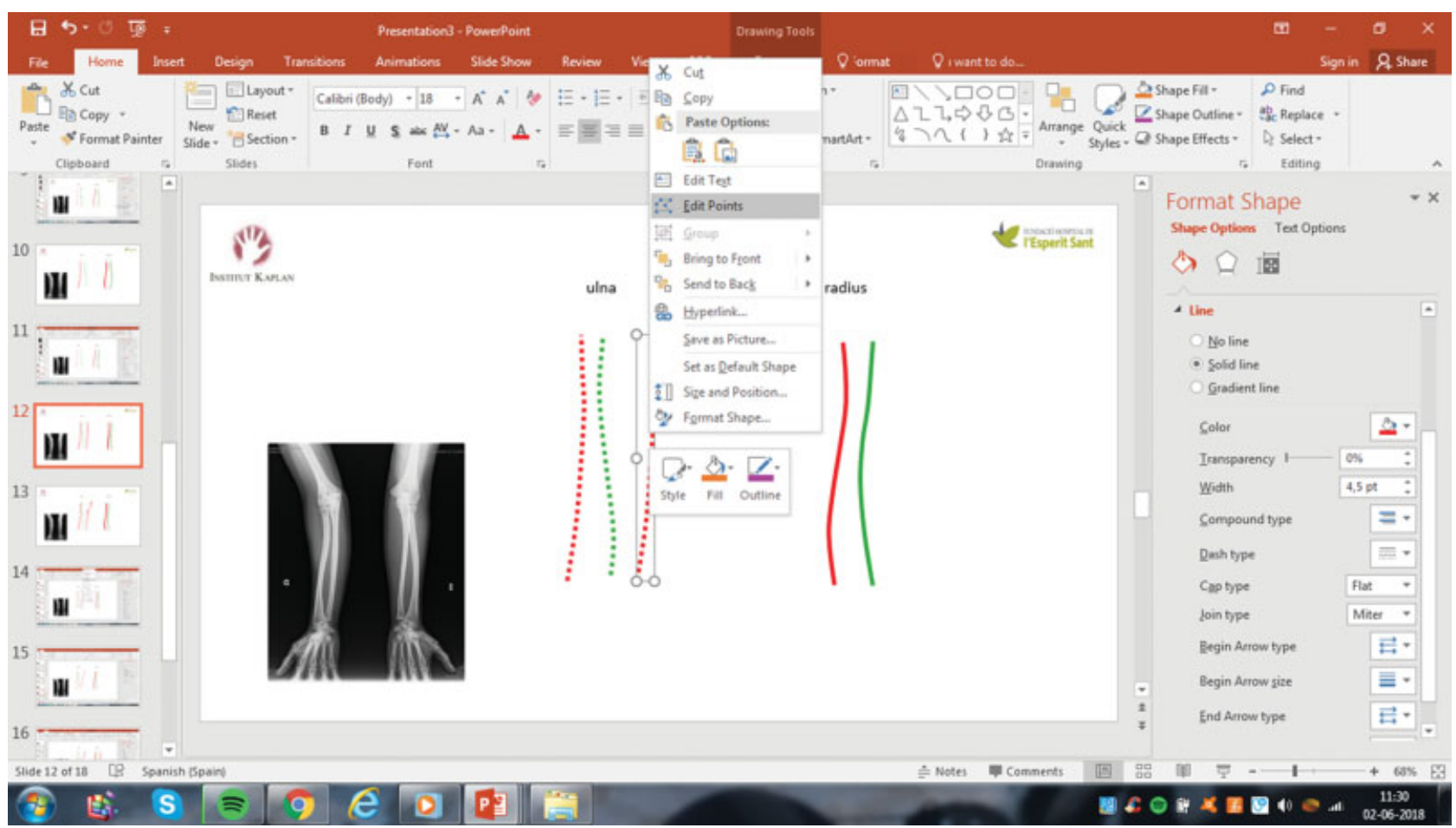

Fig. 6 Editing tool. Rotate the cut deviated bone to match the reverse normal bone.

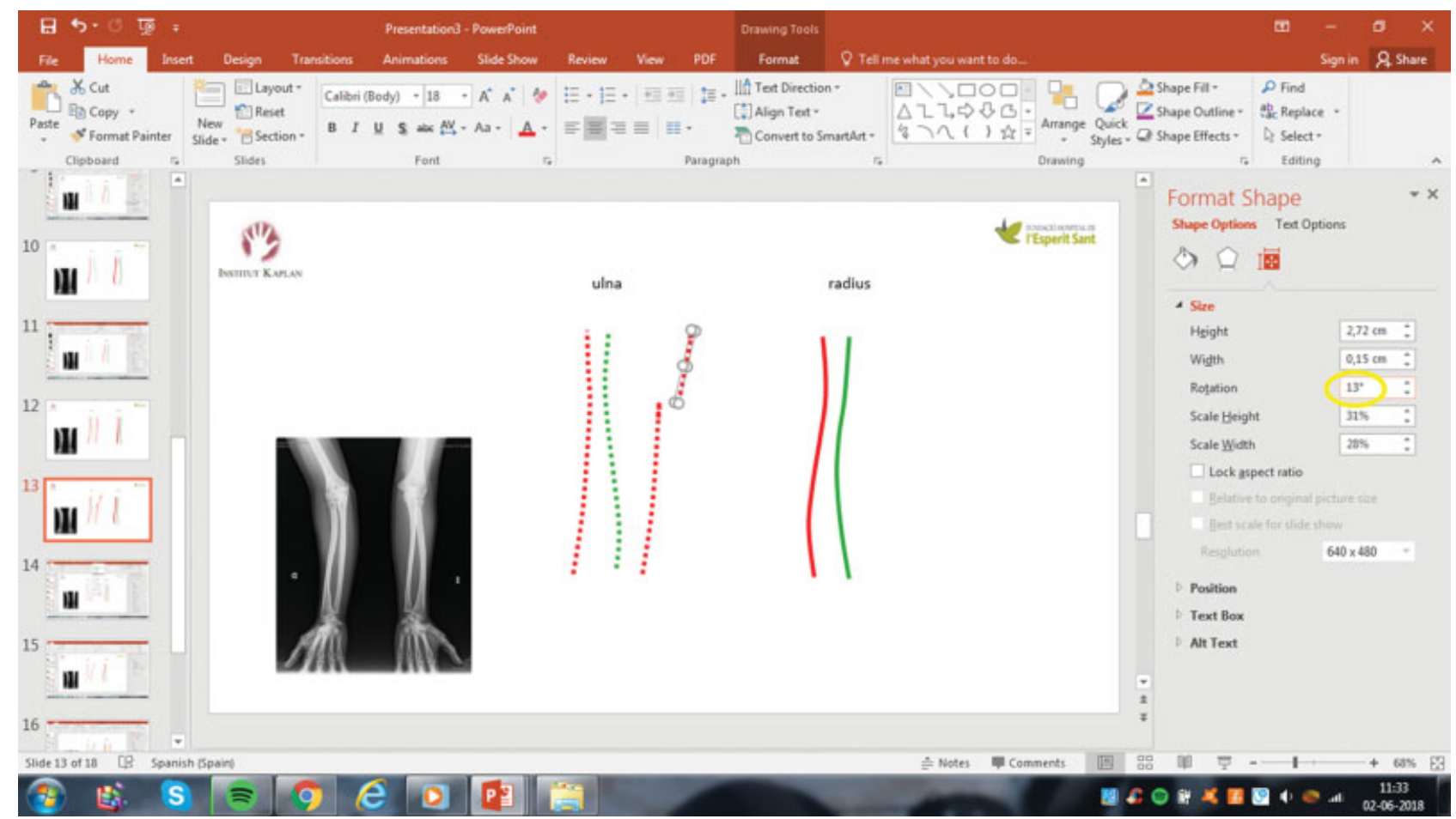

Fig. 7 Angulation needed will show in the rotation box.

\section{Case 4}

The patient was a 31 years/o male. Monteggia fracture treated with a cast in 2011. Pronosupination deficit with anterior subluxation of the radial head. A corrective osteotomy with plate in ulna was performed, with consolidation achieved at 8 months. Final deficit of $30^{\circ}$ pronation

\section{Case 5}

The patient was a 15 years/o male. Juvenile soccer player. In August 2005, he suffered a radius fracture, treated orthopedically with a cast. Afterwards, the pronosupination motion was limited, with unstable distal radial ulnar joint (DRUJ). An open-wedge osteotomy was calculated and performed in 
AP Supination



ulna

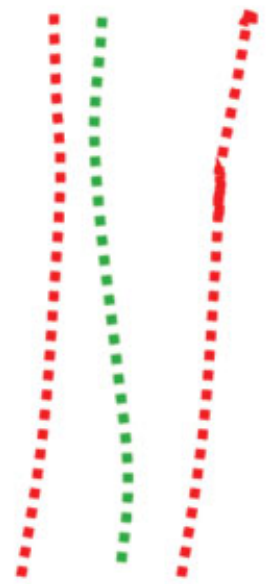

$13^{\circ}$ radial

angulation radius

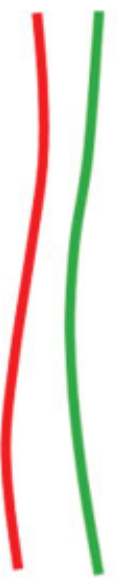

Fig. 8 Final view for the correction needed for ulna.

\section{Lateral}
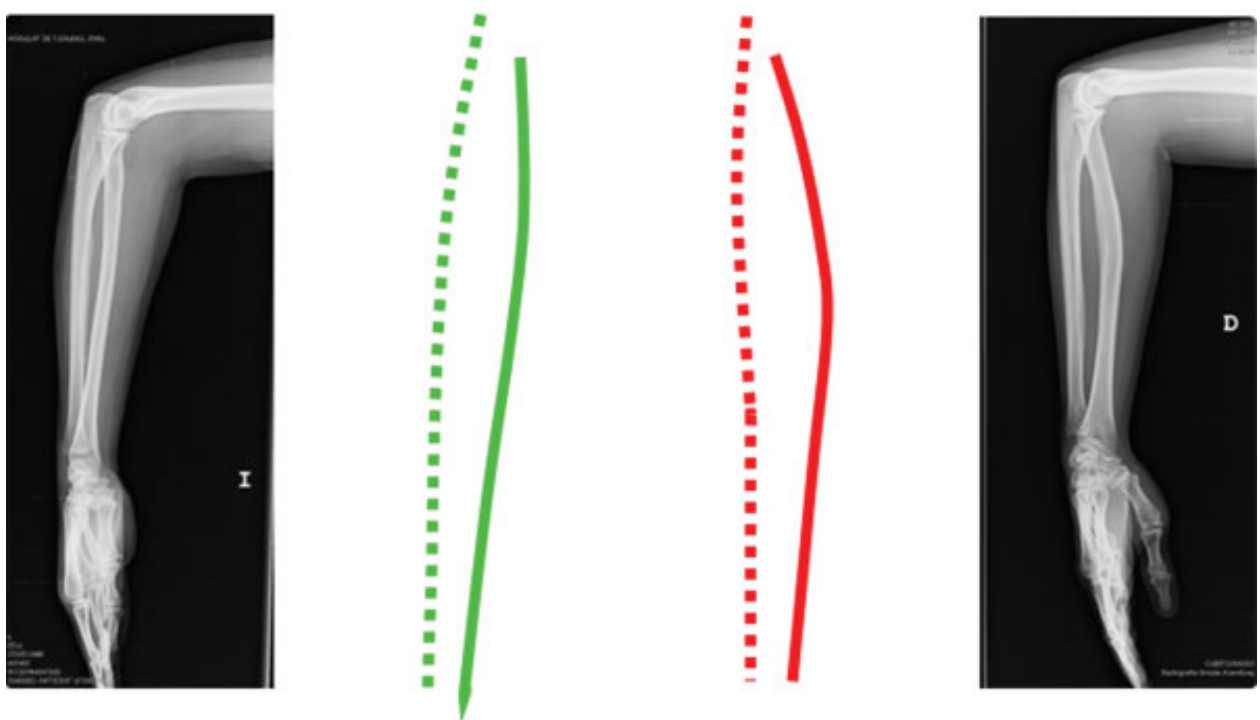

Fig. 9 Preparation for radial calculation in lateral view. Red for the right arm, green for the left. Solid lines stand for the radius and dotted ones for the ulnae.

2017. Six months after the surgery, the pronosupination motion was complete.

\section{Case 6}

The patient was a 43 years/o male. Radius fracture in 2012 , failed surgery in 2 opportunities. In 2013, an open-wedge surgery was performed, with better pronosupination of the forearm but still with some restrictions.

\section{Discussion}

Although osteotomies in the upper limb are exceptional, sometimes the patient needs to undergo this procedure to correct malalignment and regain normal function of the extremity.
Many different approaches to this matter have been done, from the trigonometric method of Paley to the more modern 3D printing and maquetting. ${ }^{3,6}$ However, in a globalized world, not every surgeon has access to this modern way of planning, and some even prefer the old methods.

We presented a method that has many advantages: based on plain X-rays and using a widespread software like PowerPoint, simple to follow, and close to the original method of Paley, familiar to many orthopedic surgeons.

We tested the calculation in six patients, with a good correlation between the planning and the surgery. In one case, it was done with a 3D model, since it was both bones in the forearm, but in the rest of the cases, this model was not done, also with good results (-Table $\mathbf{1}$ ). 


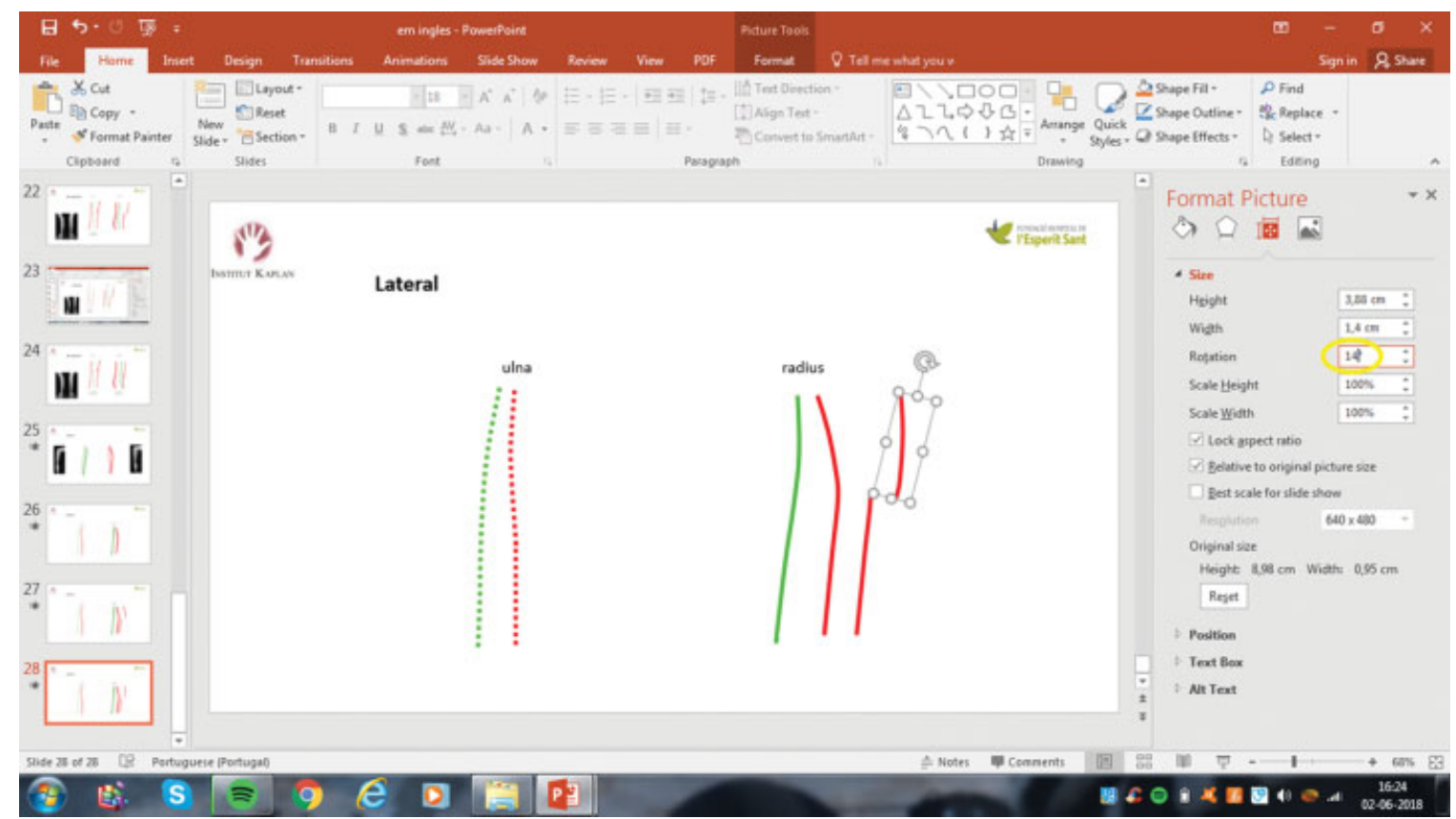

Fig. 10 Duplicate and rotated normal bone. With the edit point box, rotation at the intersection of deviated bone with reverse normal bone.



Fig. 11 Final angulation needed for radius.

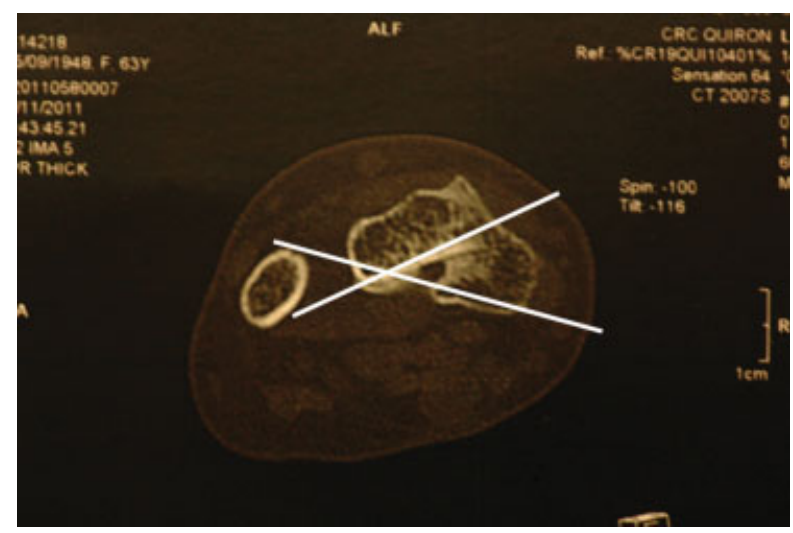

Fig. 12 These are the lines to work with in case a transverse correction should be needed. radius



$14^{\circ}$ dorsal

angulation
Table 1 Patients with a corrective osteotomy, calculated with the Giro technique. Pronosupination pre and postsurgery

\begin{tabular}{|l|l|l|l|l|l|l|l|}
\hline Id & Gender & Age & $\begin{array}{l}\text { Sup } \\
\text { pre }\end{array}$ & $\begin{array}{l}\text { Pron } \\
\text { pre }\end{array}$ & $\begin{array}{l}\text { Sup } \\
\text { post }\end{array}$ & $\begin{array}{l}\text { Pron } \\
\text { post }\end{array}$ & $\begin{array}{l}\text { Gain } \\
\text { (total arc) }\end{array}$ \\
\hline 1 & $\mathrm{~F}$ & 27 & 40 & 5 & 90 & 80 & 125 \\
\hline 2 & $\mathrm{M}$ & 32 & 25 & 50 & 80 & 70 & 75 \\
\hline 3 & $\mathrm{M}$ & 23 & 70 & 10 & 65 & 70 & 75 \\
\hline 4 & $\mathrm{M}$ & 31 & 5 & 30 & 90 & 65 & 125 \\
\hline 5 & $\mathrm{M}$ & 15 & 45 & 60 & 80 & 75 & 50 \\
\hline 6 & $\mathrm{M}$ & 43 & 45 & 45 & 70 & 80 & 60 \\
\hline
\end{tabular}

Abbreviations: F, female; Id, case number; M, male; Post, postsurgery; Pre, presurgery; Pron, pronation; Sup, supination. 


\section{Conclusion}

We believe that PowerPoint is useful in the preplanning stages of an osteotomy. It helps to determine the degrees to correct, and the CORA; it is easy to handle, and it does not need any special training or expensive equipment. Therefore, it is a valuable tool in the general practice.

\section{Conflicts of Interest}

The authors declare that there were no conflicts of interest.

\section{References}

1 Warnock KM, Johnson BD, Wright JB, Ambrose CG, Clanton TO, McGarvey WC. Calculation of the opening wedge for a low tibial osteotomy. Foot Ankle Int 2004;25(11):778-782

2 Ribeiro $\mathrm{CH}$, Severino NR, Fucs PM. Preoperative surgical planning versus navigation system in valgus tibial osteotomy: a crosssectional study. Int Orthop 2013;37(08):1483-1486
3 Mader K, Koolen M, Flipsen M, van der Zwan A, Pennig D, Ham J. Complex forearm deformities: operative strategy in posttraumatic pathology. Obere Extrem 2015;10(04):229-239

4 Rolim EL, Torres MR, Silva MR, Lima FR, Aguiar JL. Simplified calculation for corrective osteotomies of long bones. Acta Ortop Bras 2016;24(05):253-258

5 Paley D, Herzenberg JE, Tetsworth K, McKie J, Bhave A. Deformity planning for frontal and sagittal plane corrective osteotomies. Orthop Clin North Am 1994;25(03):425-465

6 Murase T, Oka K, Moritomo H, Goto A, Yoshikawa H, Sugamoto K. Three-dimensional corrective osteotomy of malunited fractures of the upper extremity with use of a computer simulation system. J Bone Joint Surg Am 2008;90(11):2375-2389

7 Leong NL, Buijze GA, Fu EC, Stockmans F, Jupiter JB; Distal Radius Malunion (DiRaM) collaborative group. Computer-assisted versus non-computer-assisted preoperative planning of corrective osteotomy for extra-articular distal radius malunions: a randomized controlled trial. BMC Musculoskelet Disord 2010;11:282

8 Jones JK, Krow A, Hariharan S, Weekes L. Measuring angles on digitalized radiographic images using Microsoft PowerPoint. West Indian Med J 2008;57(01):14-19 